\title{
Muscle development in the marbled crayfish-insights from an emerging model organism (Crustacea, Malacostraca, Decapoda)
}

\author{
Günther Jirikowski • Sabine Kreissl • Stefan Richter • \\ Carsten Wolff
}

\begin{abstract}
The development of the crustacean muscular system is still poorly understood. We present a structural analysis of muscle development in an emerging model organism, the marbled crayfish - a representative of the Cambaridae. The development and differentiation of muscle tissue and its relation to the mesoderm-forming cells are described using fluorescent and non-fluorescent imaging tools. We combined immunohistochemical staining for early isoforms of myosin heavy chain with phallotoxin staining of F-actin, which distinguishes early and more differentiated myocytes. We were thus able to identify single muscle precursor cells that serve as starting points for developing muscular units. Our investigations show a significant developmental advance in head appendage muscles and in the posterior end of the longitudinal trunk muscle strands compared to other forming muscle tissues. These findings are considered evolutionary relics of larval developmental features. Furthermore, we document the
\end{abstract}

Communicated by S. Roth

G. Jirikowski $(\bowtie) \cdot S$. Richter

Universität Rostock, Institut für Biowissenschaften/Allgemeine und Spezielle Zoologie,

Universitätsplatz 2,

18055 Rostock, Germany

e mail: guenther.jirikowski@uni rostock.de

\section{Wolff}

Humboldt Universität zu Berlin, Institut für Biologie, AG Vergleichende Zoologie,

Philippstr.13,

10115 Berlin, Germany

S. Kreissl

Universität Konstanz,

Fachbereich Biologie,

78457 Konstanz, Germany development of the muscular heart tissue from myogenic precursors and the formation and differentiation of visceral musculature.

Keywords Marmorkrebs · Development .

Muscle precursor $\cdot$ Myogenesis $\cdot$ Evolution

\section{Introduction}

Malacostracans exhibit a diverse set of developmental modes. Adult individuals can arise from a free-swimming nauplius larva that carries only three appendage-bearing body segments and passes through a series of further larval stages. This is the case in Dendrobranchiata and Euphausiacea. The hatching of more advanced larvae, zoea- or zoea-like larvae, is observed in Stomatopoda, Bathynellacea, Amphionidacea, Caridea, Stenopodidea, and Reptantia (Richter and Scholtz 2001). Peracarida, freshwater crayfish, and Leptostraca share the feature of direct development, in which juveniles hatch as a premature version of the adult.

The development of the muscle system can be assumed to reflect this diversity, due not least to its importance in larval locomotion. At the same time, the mesodermal tissue from which postnaupliar muscles are formed originates in the same way in all malacostracan representatives: postnaupliar body segments are generated by teloblastic proliferation from specific posterior cells, the mesoteloblasts. Segmental primordia of embryonic mesoderm are laid down in a process of repeated asymmetrical division of these eight cells. The cells are arranged in a transverse row, as in the Peracarida (Dohle 1970; Dohle 1972; Scholtz 1990 ) or in a ring around the gut primordium as seen, for example, in Decapoda (Scholtz 2002). General aspects of mesoderm formation have been described in the decapods 
Palaemonetes varians (Weygoldt 1961), Heptacarpus rectirostris (Oishi 1959), Pagurus samuelis, Hemigrapsus sanguineus (Oishi 1960), Cherax destructor (Scholtz 1992), and the amphipods Gammarus pulex (Scholtz 1990; Weygoldt 1958) and more recently in Orchestia cavimana and Parhyale hawaiensis (Wolff and Scholtz 2002; Gerberding et al. 2002).

This particular mode of mesoderm formation leads to a gradient of developmental progress along the AP axis. Because the segmental mesoderm primordia each represent genealogical entities that are serially homologous (Scholtz 2002), different developmental stages can be compared, even within one specimen. This way, valuable data is added to the strictly temporal tracing of development and differentiation.

There are few published studies on the morphogenesis of the muscle system. Recent work on the amphipod $P$. hawaiensis has revealed that orthologs of muscledetermining genes are expressed in a segmental fashion as the germ band elongates (Price and Patel 2008). This pattern is expected, if muscle progenitors are considered derivatives of the mesoteloblast cells. Phallotoxin staining of dendrobranchiate embryos (Kiernan and Hertzler 2006) revealed that development of the muscle apparatus in this species is dominated by the formation of the nauplius locomotor musculature. We wanted to describe embryonic muscle formation in a malacostracan that does not pass through larval stages but develops directly. Development seems to be highly conserved among crayfish taxa (Vilpoux et al. 2006). The marbled crayfish has received a great deal of attention in recent years due to its strictly parthenogenetic mode of reproduction, a feature never previously observed in or described for decapods. The ease with which this species can be reared and egg material obtained has led many authors to propose the establishment of this animal as model system for developmental studies (Alwes and Scholtz 2006; Scholtz et al. 2003; Seitz et al. 2005; Vogt et al. 2004).

Kreissl et al. (2008) introduced an antibody with a particularly high sensitivity to the heavy chain of the myosin protein which permits the early visualization of muscle pioneer cells in Isopoda. We apply the same method to the marbled crayfish and combine it with phallotoxin staining of F-actin and fluorescent detection systems to document the process of muscular development.

Moreover, the study of insect myogenesis has led to the discovery of single muscle founder cells (Steffens et al. 1995, Xie et al. 1994) and to the establishment of the "founder cell model" of myogenesis, which has been most thoroughly tested on Drosophila melanogaster. According to this model, mesodermal muscle progenitor cells are specified that undergo division to form muscle pioneer cells (termed "muscle founder cells" in the fly). Muscle pioneer cells already show muscle-specific protein expression and have the potential to recruit undifferentiated mesodermal cells, termed "fusion-competent myoblasts". Fusion of muscle pioneers and fusion-competent myoblasts give rise to syncytial muscle precursors, which eventually differentiate into functional myotubes (Baylies et al. 1998; Paululat et al. 1999; Campos-Ortega and Hartenstein 1997). In this paper, we hope to clarify if certain aspects of insect myogenesis also hold true for the crayfish.

High resolution analysis techniques such as confocal laser scanning microscopy and computer aided 3D visualization and editing make it possible to look at muscular development on a cellular level and greatly facilitates the presentation of the results. The conserved segment polarity factor Engrailed is a general marker for segment boundaries in embryonic development and can be visualized with the help of the cross reactive antibody Mab4D9 (Developmental Studies Hybridoma Bank, University of Iowa) (Abzhanov and Kaufman 2000). Since somites of the malacostracan trunk are initially formed as single rows of cells and exhibit conserved stereotypic cell division patterns in the ectoderm (Scholtz 1992), we use this marker to assign developing muscle components to their precise location within the segment.

\section{Methods}

Embryo collection

We used the staging system established by Alwes and Scholtz (2006) to identify embryonic stages during the collection of series. Embryos were collected from the pleopods of gravid females twice a day for 10 days, starting on day 5 after egg deposition (embryonic stage 3, which corresponds to the egg-nauplius). The chorion and the vitelline membrane were removed by hand dissection. Fixation was carried out in $4 \%$ paraformaldehyde (Electron Microscopy Sciences)/PBS (1.86 mM NaH $\mathrm{PO}_{4}, 8.41 \mathrm{mM} \mathrm{Na}_{2} \mathrm{HPO}_{4}, 175 \mathrm{mM} \mathrm{NaCl}$, $\mathrm{pH}$ 7.4). For fluorescent staining and CLSM or regular transmission microscopy, the soft yolk mass was dissected from the embryos. Additionally, eggs were fixed by boiling in PBS for $10 \mathrm{~min}$ at $85^{\circ} \mathrm{C}$ followed by incubation in paraformaldehyde. This procedure preserves the entire yolk, which hardens at high temperatures, and was only used for the combination of staining and signal detection using the alkaline phosphatase system.

Generation of monoclonal antibodies and characterization of the antibody $017 \mathrm{C} 5$

A library of monoclonal antibodies against proteins of meso- and metathoracic locust muscles (flight muscles and 
intrinsic walking muscles) was generated and screened as described earlier (Kreissl et al. 2008). In brief, a crude myosin extract (Dalbis et al. 1979) of locust muscles was used as the antigen to immunize mice. Hybridoma clones were screened and subsequently selected by enzyme-linked immunosorbent assay, immunostaining on cryosections of native and paraformaldehyde-fixed locust muscles, as well as western blot analyses. The antibodies generated against meso- and metathoracic locust muscle proteins were also screened for their binding affinity to muscle tissue or myosin of rabbits. The supernatant of the clone $016 \mathrm{C} 6$ was also screened for binding to proteins of the isopod crustacean Idotea emarginata (Kreissl et al., 2008). For the identification of the antigen of monoclonal antibodies produced by clone $017 \mathrm{C} 5$ in western blots, the crude myosin extracts of locust flight and leg muscles from the meso- and metathorax and myosin from rabbit muscle (SIGMA, Deisenhofen, Germany, cat. nr. M1636) were separated by sodium dodecyl sulfate-polyacrylamide gel electrophoresis (Fig. 1a). The lanes of $10 \%$ linear gels were

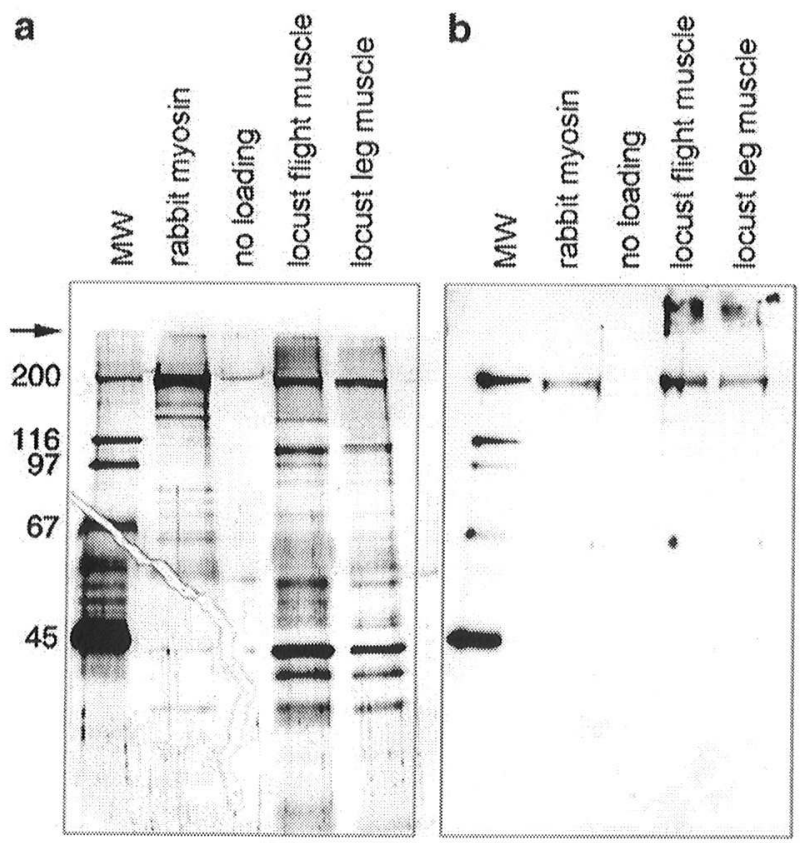

Fig. $1017 \mathrm{C} 5$ specifically binds to myosin heavy chains. a Separation of muscle proteins on $10 \%$ SDS PAGE. Lanes were loaded as follows: molecular weight markers $(M W)$, rabbit myosin, no loading to prevent spillover of rabbit and locust proteins, muscle homogenates of $L$ migratoria flight muscle, and muscle homogenates of L. migratoria walking muscles. Proteins were silver stained. Numbers at the left indicate molecular weight in kilodalton and the arrow indicates start of the separation gel. Myosin heavy chains are prominent at MW of about $200 \mathrm{kDa}$. b Identification of the 017C5 antigen by western blot analysis of a gel run in parallel with that shown at the left reveals myosin heavy chain of rabbit muscle and locust muscle. Note that the antibody also binds to non dissociated myosin heavy chain multimeres in the loading gel which did not enter the separation gel loaded with 1-2 $\mu \mathrm{g}$ protein, and gels were run according to standard techniques. The proteins were transferred to cellulose nitrate membranes (Protran, Schleicher \& Schuell $\mathrm{GmbH}$, Dassel, Germany) and selective binding of cell culture supernatant of the clone $017 \mathrm{C} 5$ at a dilution of 1:10 was detected with the IgG-ABC-ELITE-POD kit (Vector Labs) using ECL (Pierce) as a substrate. Molecular weight markers were biotinylated, allowing direct detection by the $\mathrm{ABC}$ reagent in the western blots.

\section{Specificity of antibodies 016C6 and 017C5}

016C6 antibodies have previously been shown to be specific for myosin-HCs of Locusta migratoria, I. emargi nata (Isopoda), Eriphia spinifrons (Decapoda), and to the slow myosin-HC-I isoform of rabbit muscles (Kreissl et al. 2008). Screening the supernatant of monoclonal hybridoma cell line $017 \mathrm{C} 5$ for binding affinity to muscle proteins in western blots revealed strong labeling of locust muscle proteins with an apparent molecular weight of about $200 \mathrm{kDa}$ and myosin heavy chains of rabbit muscle (Fig. 1b). These findings indicate that the monoclonal antibody 017C5 exhibited prominent affinity for myosin$\mathrm{HC}$ of vertebrates and arthropods. In addition, 017C5 strongly binds to high molecular weight compounds of the locust muscle extract which most likely represent nondissociated dimers or multimeres of myosin-HC (Fig. 1b). We used Mab 017C5 as a general marker for differentiating muscle cells already containing myosin heavy chains. It was particularly useful for staining of the cardiac and gut muscle cells.

\section{Antibody staining}

Embryos were washed prior to staining in PBT (PBS pH 7.4; $0.3 \%$ bovine serum albumin (MERCK Darmstadt), 0.3\% Triton X-100; $1.5 \%$ dimethylsulfoxide) for $3 \mathrm{~h}$ and incubated for $1 \mathrm{~h}$ in PBT and 3\% normal goat serum (Dako) to block unspecific binding sites. Incubation was carried out overnight at $4^{\circ} \mathrm{C}$ in a $1: 10$ dilution of supernatant in PBT. Signal detection was performed using mouse antibodies (Cy3labeled goat-AffiniPure anti-mouse IgG $\mathrm{H}+\mathrm{L}$, Jackson Immunoresearch or alkaline phosphatase conjugated AffiniPure goat anti-mouse IgG $\mathrm{H}+\mathrm{L}$, Jackson Immunoresearch). Embryos were washed in PBT for $3 \mathrm{~h}$ to remove unbound antibody and incubated in blocking solution for $1 \mathrm{~h}$, as described above. Secondary antibodies were diluted 1:200 and applied as described for the primary antibody incubation. Washing in PBT for $4 \mathrm{~h}$ followed to remove unbound antibody. Embryos were then counterstained with Hoechst (Bisbenzimide, Biochemica) $1 \mu \mathrm{g} / \mathrm{ml}$ in PBS and Alexa A488-conjugated phalloidin (Invitrogen Molecular Probes) to visualize nuclei and F-actin. All washing steps were carried 
out on a horizontal shaker (neoLab1). Objects were mounted on microscopy slides or cover slips in glycerol containing $2.5 \mathrm{mg} / \mathrm{ml}$ of the anti-bleaching agent Dabco (ROTH).

\section{Microscopy}

Light microscopy was carried out using an Axio-Imager M1 compound microscope and a Discovery V12 stereo microscope, both equipped with an Axio-Cam ICc3 camera (Zeiss, Jena). Image stacks were taken using a Leica DM IRE2 confocal laser scanning microscope equipped with a Leica TCS SP2 AOBS laser scanning unit. Step sizes ranged from 0.35 to $1.0 \mu \mathrm{m}$. Late-stage embryos could not be scanned at $z$-depths of more than $50 \mu \mathrm{m}$ so they were mounted on $60 \mathrm{~mm}$ cover slips and scanned from both sides. The image stacks were then inverted and aligned manually using "Autoaligner" (Bitplane AG, Switzerland). Subsequent analyses were performed with "IMARIS 6.4.0" (Bitplane AG, Switzerland). All figures were compiled using "Corel Graphic Suite XIII". The description of myogenesis is based on the staging system established by Alwes and Scholtz (2006).

\section{Results}

In crayfish development, the tissues of the prospective trunk and appendages are first laid down on the surface of the large yolk mass. The caudal papilla, the posterior part of the embryo containing the ectoteloblast and mesoteloblast cells that proliferate the cell material of new body segments, is flexed anteriorly after stage 3. A specimen providing a ventral view of the segments anterior to the fold therefore displays the segments posterior to the fold from a dorsal perspective (for orientation see Fig. 2a-c).

A series of embryos stained with phalloidin is shown in Fig. 2d-h. Anti-myosin-HC 016C6 has proven to effectively stain muscle-forming cells before myofibrils have formed within the cytoplasm. This is possibly due to the considerable affinity between these antibodies and monomeric forms of the protein. Mononucleate muscle pioneers can therefore be identified in the earliest stages of the differentiation process by the increase in monomeric myosin in the cytoplasm. As differentiation continues, fibrous patterns are also visible, caused by the emerging filamentous actin (F-actin) signal. As a result, it was possible to identify both striated and non-striated muscles in various embryonic tissues. Since phalloidin binds specifically to F-actin, its use in combination with the myosin antibodies makes it possible to identify muscle pioneer cells and precursors that differ in their grade of differentiation. The fluorescent detection system used for signal visualization in anti-myosin-HC stains only produced poor results in embryos younger than stage 5, but it was possible in these specimens to detect a signal using the alkaline phosphatase system.

We have adapted the terminology of the "founder cell model" of insect myogenesis for description of the cell types observed in crayfish muscle development. Single cells positively stained for myosin-HC which lay down a scaffold for muscle formation early in development are termed "muscle pioneer cells". The multicellular or syncytial primordia arising from these pioneers are referred to as muscle precursors. Unfortunately, we cannot say if fusion has taken place in the muscle precursors. The undifferentiated mesodermal cells that together with muscle pioneer cells, form the precursors, are termed "myoblasts". We want to emphasize, however, that the common use of insect terms for crustaceans is used to maintain the simplicity of the descriptions but must not be interpreted as a statement of homology between insect and crustacean muscleforming cells.

\section{Development of cephalic muscles}

Muscle precursors of the head segments are first detected by immunostaining and after stage 4 by a combination of immunostaining and phalloidin. The role of the precursors in the juvenile is not always clear. To describe precursors observed here, we therefore use a code of lower case letters and numbers which specifies the body segment in which the primordium is seen (designated by its characteristic appendage, e.g., antenna 1), the orientation of the forming muscle primordium in relation to the appendage bud (lateral or medial), and a number that further specifies the primordium if more than one is present in one segment. $a 212$, for example, represents the second laterally orientated muscle precursor in the antenna 2 segment.

Initiation of muscle differentiation appears late in stage 3 in groups of mesodermal cells which form muscle precursors in the head segments of antenna 1 (al $\mathrm{ml}$ ), antenna $2(a 2 l 1, a 2 l 2)$, the mandible ( $m d \mathrm{ml}$, $m d l 1$ ), and maxilla 1 ( $m x l l l$ ) (Fig. 3a). These precursors display significant myosin-HC immunoreactivity. At stage 4, the precursors also show a phalloidin signal. al $\mathrm{ml}$ reaches anterolaterally from the ventral periphery of the stomodaeum to a region anterior to the bud of antenna 1 (Fig. 3b). It contains just two positively stained cells whose nuclei are positioned in the middle of the muscle precursor (Fig. 3c). The nuclei of $a 2 l 1, a 2 l 2$, and $m d l 1$ are more evenly distributed within these precursors (Fig. 3d). At stage 5, e $\mathrm{ml}$, a muscle precursor reaching from the anterior of the stomodaeum to the medial region of the optic lobe, arises (Fig. 3e). The posterolaterally 

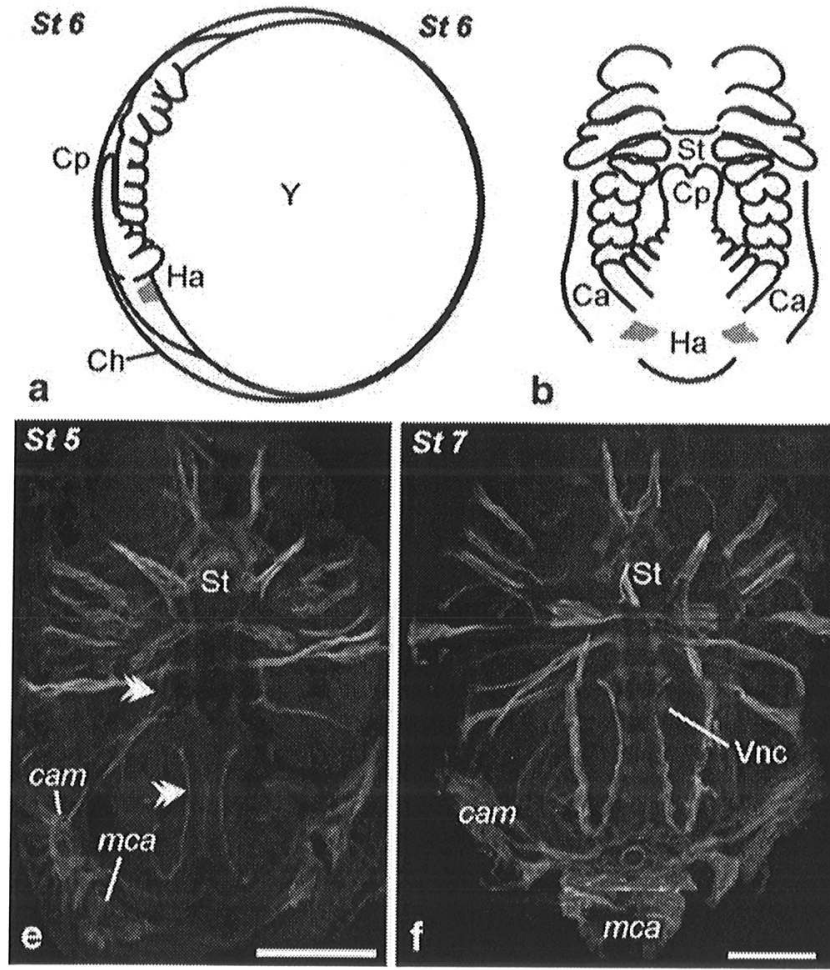

Fig. 2 Overview of Marmorkrebs' myogenesis. a Schematic drawing of an egg in lateral view. b Drawing of an embryo (without yolky mass) in ventral view. c Stereomicroscopic image of embryo as in b, ventral view of living egg with the right half of the embryo outlined in white. d h Overviews of phalloidin signal in embryos of stages 5 to 9. d First cephalic muscles (arrowheads) around the stomodaeum ( $S t$ ). Strong signal is seen in the early ventral nerve chord $(V n c)$. e Progenitors of carapace muscles (cam), myocard ( $\mathrm{mca}$ ), and first longitudinal muscle fibers (double arrows) are visible. f Carapace anlagen muscles (cam)

protruding precursor, $m x l l l$, can be seen anteriorly of the anlagen of maxilla 1 . At stage 7 , a cephalic muscle precursor, $m \times 2 l 1$, is added in the maxilla 2 segment (Fig. 3f). al $\mathrm{ml}$ now contains multiple fibrous elements (Fig. $3 g$ ). The median endings of $a 2 l l$ and $a 2 l 2$ clearly show an insertion into the bud of antenna 2 (Fig. 3h). $m d$ $m l$ is partly positioned within the mandibular bud, completely filling out this appendage anlage. At this stage, it contains a comparatively large number of cells, going by the number of nuclei within the primordium (Fig. 3i). At stage 9, the median ends of $e m l$ and $a l ~ m l$ are seen in close proximity to the stomodaeum and adjacent pharynx (Fig. 3j). We assume that they form pharyngeal dilator muscles, as seen in myosin heavy chain staining in dissected juveniles (data not shown). All muscle precursors display a significant portion of condensed fibrous elements, although striation is still difficult to make out in most areas. $a 2 l l$ and $a 2 l 2$ take a more lateral position. The same applies to $m d l l$, which is now subdivided into two distinct units. $m d m l$ exhibits a


have expanded anteriorly and posteriorly. $\mathrm{g}$ Musculature of the carapace anlage has formed a longitudinal band on each side of the embryo. Intrinsic muscles of the postnaupliar appendages (asterisks) are visible. h Dorsal view of same embryo. Longitudinal pleon musculature is divided into multiple subunits. Letters in the upper left corners identify the developmental stages; $\mathrm{Ca}$ carapace anlage, cam carapace anlagen muscles, $C h$ chorion, $C p$ caudal papilla, $H a$ heart anlage, $m c a$ myocard anlage, $\operatorname{slp}$ subunits of longitudinal pleon musculature, $S t$ stomodeum, $Y$ yolk. Scale bars, $200 \mu \mathrm{min}$ all panels

bipartite structure. This precursor most likely represents a future adductor and possible rotator muscle of the mandible (Fig. 3j). The subsequent appendage anlagen also reveal intrinsic muscle precursors which, however, are not the subject of this study.

Development of longitudinal muscles

The longitudinal muscles of the trunk, which are especially prominent in the complex muscle apparatus of the adult pleon, are first laid down as a pair of undivided muscle strands in the embryo. Their development involves a transition from segmental single cell pioneers to multicellular precursors that form multiple single muscles.

In stage 3 embryos, a row of spindle-shaped pioneer cells exhibiting myosin immunoreactivity is found ( $\mathrm{mp}$ in Fig. 3a). The anteriormost pioneer is located medially between the buds of antenna 2 and the mandible. A posterior pioneer between the limb buds of the mandible and maxilla 1 follows. At stage 4, a continuous myosin- $\mathrm{HC}$ 


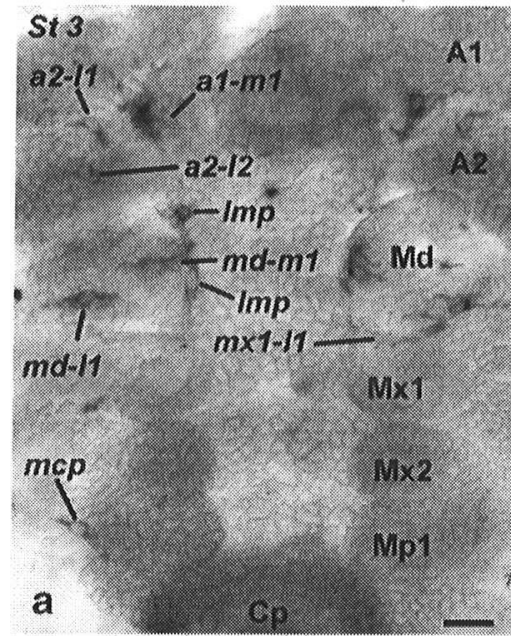

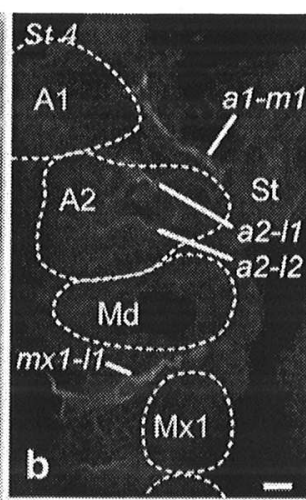
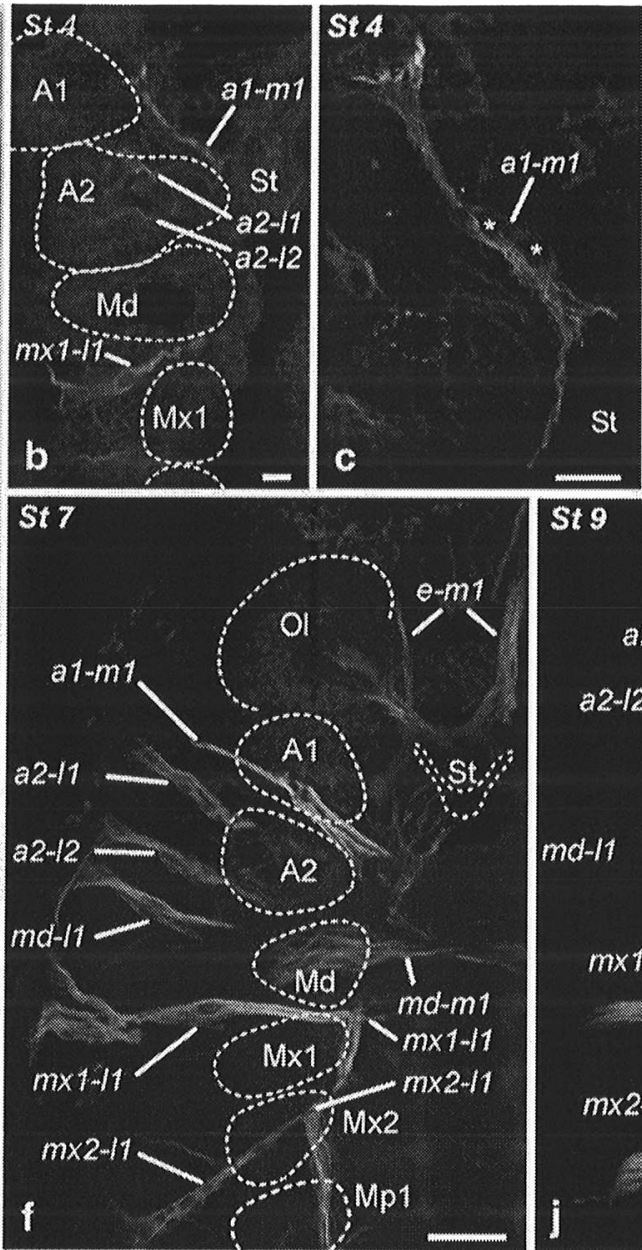

\section{St 9}
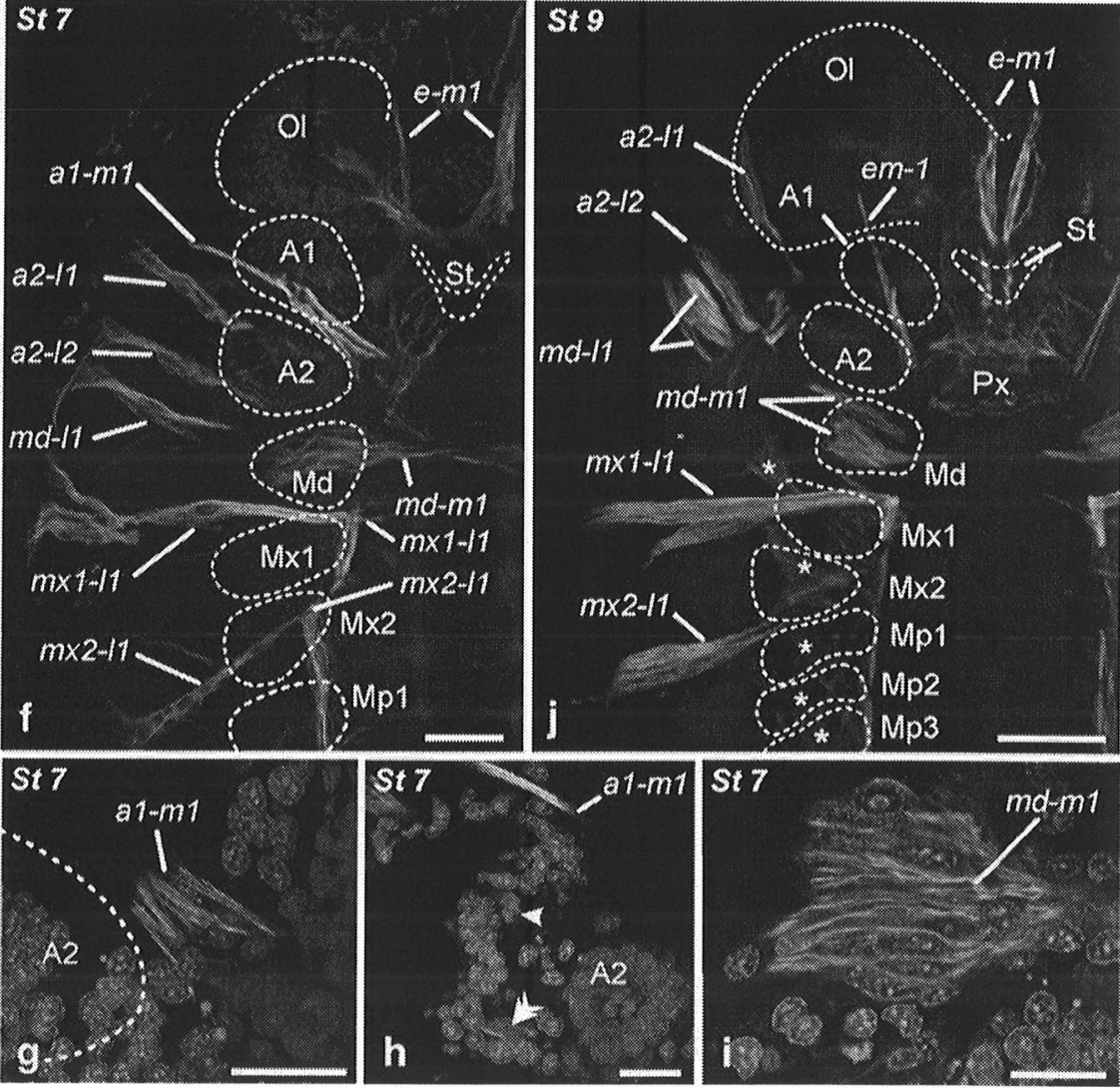

Fig. 3 Embryonic muscles in the left half of the head anlage. Signal detection of anti myosin $\mathrm{HC}$ was performed by alkaline phosphatase reaction (dark blue). Other samples are labeled with anti myosin $\mathrm{HC}$ (red) and phalloidin (green). The Hoechst signal (light blue) is added in $\mathbf{g}, \mathbf{h}$, and i. a Anterior half of stage 3 embryo. Muscle precursors al $m l, a 2 l 1, a 2 l 2, m d m l$, $m d l 1$, and $m x l l l$ are seen, as well as the unicellular precursors of the longitudinal muscle strand $(\mathrm{lmp})$. b Overview of anterior head segments at stage 4. Muscle progenitors $a l$ $m l$, a2 $l 1, a 2 l 2$, and $m x l l l$ are seen. c Detailed view of al $\mathrm{ml}$. Asterisks mark the positions of nuclei. d Close up of $a 2 l 1, a 2 l 2$ and $m d l l$ (the latter is not seen in b). e Muscle progenitor $e m l$ is now also visible. $f$ Overview of anterior head segments. An additional muscle progenitor $m \times 2 l l$ is seen anteriorly of the second maxilla. $m \times l ~ l l$ and $m \times 2 l l$ both intersect with the longitudinal muscle strand $(\mathrm{lm})$. g Close up of the median ending of $a 1 \mathrm{ml}$. h Connections between a2 $l 1$ (arrowhead) and a2 $l 2$ (double arrowhead) and the base of antenna 2 are seen more clearly here than in stage 5 . i Myocytes of the prospective mandible adductor muscle $m d m l$. The muscle primordium contains a comparatively large number of nuclei. $\mathbf{j}$ Muscular elements around the pharynx $(P x)$ and stomodaeum $(S t)$ become visible. The progenitor $\mathrm{em} 1$ is now connected to this complex. Progenitors of further extrinsic appendage muscles (asterisks) are seen along the anlagen of maxilla 2 and the maxillipeds. Letters in the upper left corners identify the developmental stages; $A 1$ antenna 1, $A 2$ antenna $2, C p$ caudal papilla, $h p$ prospective heart precursor, $l m$ longitudinal muscle strand, $\operatorname{lm} p$ longitudinal muscle strand precursor, $\mathrm{Ol}$ optic lobes, $M d$ mandible, $M x 1$ maxilla 1, $M x 2$ maxilla 2, $M p 1$ maxilliped 1,Mp2 maxilliped 2, Mp3 maxilliped 3. Scale bars, a d 20 $\mu \mathrm{m}$, e $\mathbf{i} 50 \mu \mathrm{m}, \mathbf{j} 100 \mu \mathrm{m}$ 
and F-actin positive longitudinal muscle strand can be seen in the cephalic and thoracic segments. The precursors are distributed metamerically along the AP axis and are each made up of two or three cells (Fig. 4b). At stage 5, the cell number continues to increase as mesodermal cells showing no myogenic signal become associated with the precursors of the segments of maxilla 1 and maxilla 2 (Fig. 4c, d). At stage 6 , the number of cells increases as development progresses and a greater number of longitudinal F-actin fibers is seen (Fig. 4e). At stage 7, the first striated fibers can be seen within the precursor. The precursors in the anterior segments are separated by segmentally reiterated subdivisions of the fiber bundles. This feature is strongest in the segment of maxilla 2 and decreases posteriorly throughout the developing thorax (data not shown). The borders between two adjacent clusters are marked by an area of particularly strong F-actin signal (Fig. 4f). At late stage 4 , a pair of parallel longitudinal muscle strands has appeared in the posterior part of the caudal papilla that protrudes anteriorly into the segment of maxilla 1 . In the segments of the prospective pereon, a continuous fiber strand is seen, containing only a few nuclei (Fig. $4 \mathrm{~g}$ ). At stage 6 , myocyte clusters are seen inside the strand positioned below the appendage bud. This is shown for pereomere 4 in Fig. $4 \mathrm{~h}$. At stage 7 , the first signs of striation can be seen (Fig. 4i). Surprisingly, the posteriormost part of the longitudinal muscle strand already shows a strong F-actin signal at stages 4 and 5. In comparison, the myogenic signal is dominated by myosin- $\mathrm{HC}$ reactivity in the more anterior segments at these stages of development. The strand in pleomeres 2 to 4 at stage 5 (Fig. 4 j) shares the features described for the pereomeres at stage 4 (Fig. 4g). At stage 6, the strand is made up of multiple cells for each pleomere. F-actin fibers are continuous, and no subdivision of the strand is seen. However, the beginning of lateral protrusions from the longitudinal strands can be observed (Fig. 4k). Also, additional cells have appeared along the strand that show only myosin-HC immunoreactivity but no F-actin signal.

In contrast to the cell clusters in the anterior parts of the strand, the nuclei of the earliest visible muscle-forming cells in the posterior segments do not show a clear segmental arrangement along the AP axis until stage 7 . This is evidenced by confocal laser scanning micrographs of Engrailed/F-actin double staining of stage 5 and 6 embryos. At these stages, only a few nuclei in the pleomeres can be clearly assigned to longitudinal muscle strand-forming precursors on the basis of their position within the F-actin positive fiber bundle (Fig. 41, m). However, these nuclei cannot be clearly assigned to a specific position within the prospective somite (visualized here by the yellow Engrailed signal which marks the posteriormost cells in the ectoderm of each body segment).
The same applies to the patch-forming cells in the pereomeres. No segmental regularity or repetition of myocyte patterns is evident (Fig. 4n, o). Furthermore, the position in which the segmental arrangement of nuclei ends can vary between stages and individuals.

\section{Posterior longitudinal muscle origin}

One particularly surprising feature of crayfish myogenesis relates to the myocytes which form the posterior end of the ventral longitudinal muscle strands. The strands elongate posteriorly as new segments bud off from the caudal papilla. The posteriormost myogenic cells of the ventral longitudinal muscle strand, the longitudinal muscle origin, lie slightly posterior to the ring of mesoteloblast cells. Even those myocytes closest to the teloblastic proliferation zone show no sign of segmental arrangement. This is visible in high magnification confocal images of Engrailed- and Factin-labeled embryos at stages 4 to 6 (Fig. 5a-h). The mesoteloblast cells themselves can be identified with the help of the parallel rows that they form with their early progeny as well as their position. The mesoteloblasts are located directly beneath the ectoteloblasts and possibly shifted to the anterior (see Fig. 5c, e, g-i). Ectoteloblasts again are readily visible as the posteriormost row in the chess-board-like pattern seen in the posterior germ band during elongation (shown in Alwes and Scholtz 2006).

Early mesoteloblast progeny show a segmental arrangement which is quickly lost in the more anterior segments. Three-dimensional reconstruction helped to visualize these cells and the relative position of the longitudinal muscle origin in embryos stained for Engrailed and F-actin (Fig. 5a, b). Since the newly formed mesoblasts proceed with their own cell divisions, only the mesoteloblasts themselves and their first three generations of descendents can be distinguished from the posterior mesoderm. The clearly visible segmentation in the mesoderm ends posteriorly to the first visible Engrailed stripe (shown yellow in Fig. 5). The posteriormost myogenic signal is seen close to the mesoteloblasts rMT1 and rMT2 on the right side of the caudal papilla of a stage 5 embryo.

The cells of the longitudinal muscle origin themselves show a loose cluster of nuclei that are significantly smaller than those of the surrounding mesoteloblasts and their segmental progeny. At late stage 4, approximately four nuclei are found, surrounded by F-actin fibers (Fig. 5c, d). These myocytes exhibit long protrusions that extend anteriorly and converge into condensed bundles. At stage 5 , nuclei in the longitudinal muscle origin cell cluster are more tightly packed and elongated (Fig. 5e, f). This suggests that myoblast fusion is taking place. The same is true of stage 6, where the F-actin signal in the longitudinal muscle origin is strongest (Fig. $5 \mathrm{~g}, \mathrm{~h}$ ). In 
addition, single nuclei are seen in the fiber strand slightly anterior to the posterior patch. The position of the longitudinal muscle origin suggests a mode of formation independent of mesoteloblast proliferation. The first detectable phalloidin signal in the caudal papilla is seen at stage 4. It is not restricted to muscle precursors, but also seen in the posterior pioneer neurons. However, this feature is not observed in later stages. Throughout all the stages, Hoechst-positive granules are seen in the caudal papilla medially of the longitudinal muscle strands (Fig. 5i). This suggests that a considerable level of apoptosis takes place in these tissues as part of the developmental process.

\section{Differentiation of the pleon muscles}

By stage 7, the formation of new segments from the caudal papilla has ceased. From stage 7 to hatching, the longitudinal muscle anlagen in the pleon undergo a transition from continuous fiber bundles to the complex muscle apparatus of the adult pleon. During this developmental process, the anterior/posterior gradient of differentiation is maintained. An overview is given in Fig. 6a-e. In addition to the ventral pair of longitudinal muscle strands, a second pair appears at this stage running parallel but dorsomedially to the previous one (Fig. 6a-e). At stage 7, it reaches as far posterior as the third pleon segment and consists of segmentally arranged cells and cell clusters within the dorsal mesoderm that are positively stained by anti-myosin-HC, but not by phalloidin at the posteriormost end (Fig. 6a, k). Unlike the posterior part of the ventral longitudinal muscle strands, dorsal muscle precursors display no stretches of non-nucleated fiber bundles at any time in development. The segmental cell patches of the ventral strand in the future pleon extend into pleomeres 6 at stage 7, but no subdivision of fibers can be seen (Fig. 6 a, 1). Many cells located closer to the body midline in the ventral strand show myosin-HC immunoreactivity but no F-actin signal. This suggests that they are not as differentiated as their more lateral counterparts. The dorsal muscle strands at early stage 8 (Fig. 6b, m) reach into pleomeres 5 . Their F-actin fibers already show clear subdivisions close to the posterior segment borders and are significantly condensed into bundles in the medial of the strand units. The lateral portions of the dorsal myocyte groups also lack phalloidin signal and are therefore interpreted as younger myocytes. In the ventral strands, the segmented clusters have also increased in size and cell number. Cells within them now show diversification in their previously parallel fiber orientation. Lateral endings are formed near the segmental furrows (Fig. 6n). At late stage 8 , the forming myotubes in the dorsal strand show striation (Fig. 60). Striated fibers are also revealed throughout the ventral strand by F-actin and myosin-HC
Fig. 4 Development of the longitudinal muscle strands from stage 4 to 7: a Schematic drawings of crayfish embryos of stages 4 to 7 with the caudal papilla and pleon anlage flexed posteriorly. The relative positions of images ( $\left(\begin{array}{l}\mathbf{0} \\ \mathbf{o}\end{array}\right)$ are indicated by colored frames. The frames of images (b o) have been colored accordingly. Longitudinal muscle strands of the right body half, stained with Anti Myosin 16C6/Cy3 (red), phalloidin/Alexa488 (green), and Hoechst (light blue). Dotted lines mark the anlagen of the appendages (in $\mathbf{b}$ and $\mathbf{i}$ ) or the segment borders (in I o). Arrowheads mark the position of myocyte nuclei. The Hoechst signal is not shown in $\mathbf{b}$ and e. b Longitudinal muscle progenitors forming a strand in the segments posterior to the mandible. Progenitors in the segment of maxilla 1 and 2 are composed of two myocytes (arrowheads). c d Close up of progenitors in the segments of maxilla 1 and maxilla 2 at stage 5. Mesodermal cells showing no myogenic signal lie close to the progenitors. e The progenitor of the longitudinal muscle strand in the segment of maxilla 1 is made up of several myocytes. $f$ Myocytes of the longitudinal muscle strand show striated fibers (double arrowhead). Borders between the myocyte clusters of the segments show particularly strong $\mathrm{F}$ actin signal (asterisks). g Early longitudinal muscle strand myocytes in pereomeres 3 to 5 (P3 5). h Myocyte clusters forming below the appendage bud in pereomere 4 . Additional cells are added to the myocyte clusters in stage 7 as shown in $\mathbf{i}$ (ventral section). Striated fibers are also seen (double arrow). j Pleon segments at stage 5. The longitudinal muscle strands only contain a few nuclei (arrowheads) but exhibit continuous F actin fibers. At stage 6, more $\mathrm{F}$ actin fibers are present, but they remain continuous. The number of myocytes has slightly increased. In the more ventral portion of the strand, some fiber elements begin to take on a more lateral orientation as seen in k (dotted line). Arrowheads mark cells of the strand showing myosin $\mathrm{HC}$ but no F Actin signal. 1 o Caudal papilla and pleon anlage labeled with anti Engrailed 4D9 (yellow), phalloidin (green), and Hoechst (light blue). Nuclei of longitudinal muscle strand myocytes are marked with arrowheads. 1 Longitudinal muscle strand in pereomere 5 and pleomeres 1 to 4 . $\mathrm{m}$ Longitudinal muscle strand in pleomeres 1 to 4 . $\mathbf{n}$ Strand containing cell patches in pereomeres 3 to 5. o Posterior longitudinal muscle origin and adjacent strand in pleomeres 1 to 4 . Letters in the upper left corners identify the developmental stages. $M x 1$ maxilla 1, $M \times 2$ maxilla 2, $M p 1$ maxilliped 1, Mp2 maxilliped 2, Mp3 maxilliped 3, Pl 5 pereomeres $15, P l 16$ pleomeres $16, C p$ caudal papilla, Imo longitudinal muscle origin. Scale bars, (b) $50 \mu \mathrm{m}$, all remaining panels $20 \mu \mathrm{m}$

staining. The developing myocytes of the ventral strand continue to diversify in terms of fiber orientation. The central muscles become distinguishable in the dorsal part of the strand as cell groups directing their fibers from a lateral position slightly posterior to the segmental furrow to a median position in the next posterior segment (Fig. 6p). Anterior to the fourth pleomere, cells form a medioventral ending approximately one third of a segment length anterior to the posterior somite border (Fig. 6q). Multiple cells that have maintained their antero-posterior orientation are also seen. F-actin fibers within muscular cell groups anterior to pleomere 5 reveal units that start at a ventromedial position at approximately half of the segment length and extend posteriorly. They insert dorsolaterally, just anterior to the segmental furrow in the following segment (Fig. 6r) and represent the early anterior oblique muscles. 


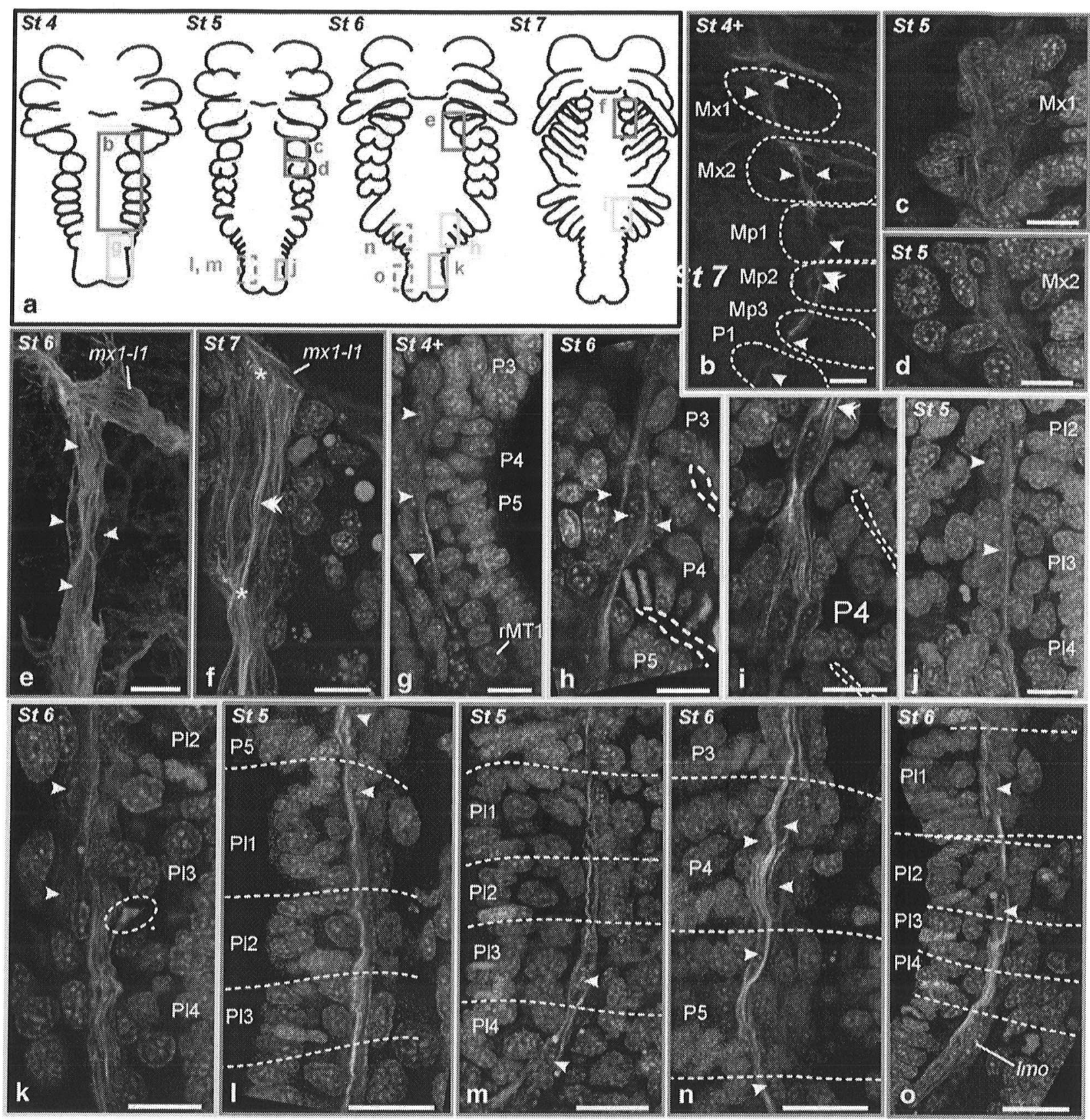



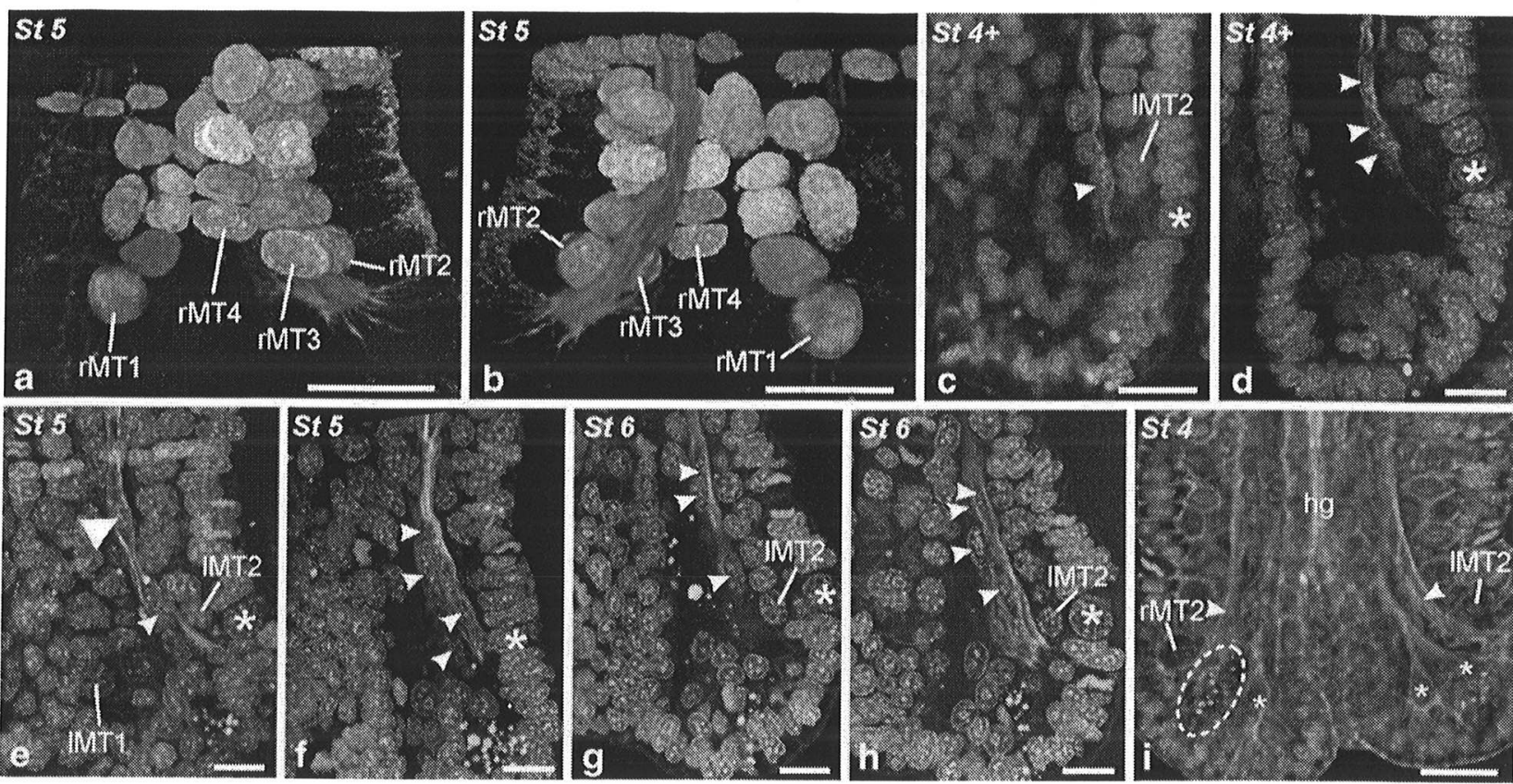

Fig. 5 Caudal papilla of embryos stained with phalloidin/Alexa488 (green) and Hoechst (light blue). In $\mathbf{a} \mathbf{h}$, only the left half of the caudal papilla is shown. a b Mesoteloblast nuclei and nuclei of early mesoteloblast progeny have been reconstructed from the Hoechst signal (white: mesoteloblasts and second generation of progeny, light blue: first and third generation). The phalloidin signal of the forming longitudinal muscle strand myocytes is shown in green. The Engrailed signal is shown in yellow. The nuclei of the remaining tissues are not shown. a Dorsal view. b Ventral view. c h Extended optical sections through the caudal papilla (left half) in ventral view. Arrowheads mark the position of nuclei, asterisks mark ectoteloblast cells. c Ventral section. d More dorsal section of the same stage. e Ventral section. A single nucleus (triangle) is seen in

the fiber strand anteriorly to the first Engrailed stripe (yellow). $\mathrm{f}$ More dorsal section of the same object. The nuclei of the myocyte patch are more elongated and tightly packed. This may be a sign of myocyte fusion. g Ventral section at stage 6 . h More dorsal section of the same object. i The F actin signal is also visible in the cytoskeleton of the cell cortex. Myocytes of the longitudinal muscle strands show phalloidin reactive processes that protrude anteriorly (arrowheads), also seen in the paired posterior pioneer neurons (asterisks). Granules of degrading DNA lie medially of the posterior myocytes (dotted line). Letters in the upper left corners identify the developmental stages. $h \mathrm{~g}$ hind gut, lMT1 4 left mesoteloblast cells $14, r M T 14$ right mesoteloblast cells 14 . Scale bars, $20 \mu \mathrm{m}$ in all panels

At late stage 9, the characteristic subunits of the pleonal muscle apparatus are more differentiated. The number of visible nuclei within the muscles has decreased significantly. The pattern of nuclei around the fiber bundles suggests that they have been moved to the periphery of the syncytial muscle precursor (Fig. $6 \mathrm{~s}, \mathrm{t}$ ). The dorsal strand muscle units have broadened and formed parallel elements. Crayfish pleon muscles reflect the general pattern of adult pleon musculature in decapods. The pleonic muscle complex comprises the muscles responsible for the flexion of the pleon, the anterior and posterior oblique pleonal muscles, the central muscles and the transverse (stator) muscles as well as the dorsal pleonal muscles which function as opposing extensor muscles (Fig. 6u, v).

\section{Cardiogenesis}

The heart, which is responsible for the distribution of hemolymph in the adult animal, represents a muscular bulb with three pairs of ostia and is surrounded by the pericardial sinus. In contrast to longitudinal muscle development, the formation of myocardial tissues in the Marmorkrebs takes place without segmentally arranged muscle precursors.

The heart-forming cells can first be clearly distinguished at stage 5 in the dorsal periphery of the third maxilliped segment, posterior to a myogenic cell group that will later form a muscular band surrounding the carapace anlage (cam) (Fig. 2c-f). Fibrous elements of the heart-forming cells stain positive for F-actin (Fig. 7b, c) and myosin-HC $017 \mathrm{C} 5$ (Fig. $7 \mathrm{f}$ ) at this stage, though the myosin-HC signal is less strong in the cellular processes. The heart primordium is passively shifted posterior as segments from the caudal papilla move anteriorly around the fold. The majority of myocyte nuclei remain close to the periphery of the caudal fold (Fig. 7f). At stage 6, the heart primordium is a contractile membrane between the epidermis and the caudal fold (Fig. 7d). At this stage, irregular contractions of the membrane can be observed in the living egg. The fine structure of the membrane reveals a network 
of F-actin positive cellular processes (Fig. $7 \mathrm{~g}$ ). By stage 7, the density of the network has increased, and the membrane has expanded anteroposteriorly and dorsally on both sides (Fig. 7e, h). In subsequent stages, the network becomes yet denser, and the fibers begin to show striation (Fig. 7i). Interestingly, the phalloidin signal is stronger in fibers facing the heart lumen (Fig. 7j). At stage 8, the dorsal extensions of the contractile network have closed underneath the dorsal epidermis, forming a contractile tube (Fig. 7k). Newly formed fibers pass through the heart lumen. Anteriorly and posteriorly, the myocardium narrows and is connected to the anterior and posterior aorta. Myosin-HC immunostaining using the alkaline phosphatase detection system on whole eggs in which only the chorion and vitelline membrane had been removed, revealed a signal in cells of the anterior aorta (Fig. 7k, 1). These cells form longitudinal rows that extend anteriorly from the heart. However, this feature is lost after stage 8 . Between stage 8 and hatching, the myocardium grows more compact, and the ostia become visible (Fig. $7 \mathrm{~m}$ ). At stages 9 and 10 , the progenitors of the alary muscles are visible under the ventral surface of the myocardium (Fig. 7n, o). Initially, two parallel muscles form on each side of the ventral heart midline, extending laterally. The muscles will eventually split, giving rise to the four muscle pairs seen in the adult (data not shown).

Visceral musculature

In living crayfish eggs, we observed slow contractions of the yolk mass after stage 8 , marking its incorporation into the forming midgut gland. Using immunostaining for myosin-HC protein on whole dechorionated eggs, we found a group of star-shaped mononucleate cells positively stained by myosin-HC antibodies of the hybridoma line 017C5. They are first seen in the periphery of the carapace anlage at stage 5 and then spread out over the surface of the yolk mass (Fig. 8a). By stage 7, the cells have formed a muscular network covering the entire yolk surface (Fig. 8b). The density of the network has increased by stage 9 (Fig. 8c) and areas with a particularly high condensation of fibers have formed. Unfortunately, we cannot say whether this involves myocyte fusion. Increasing fiber density is seen for example, in the neighborhood of the lateral cephalic muscles of the maxilla 1 segment ( $m x l$ ll). Furthermore, we found that myosin-HC antibodies of the 017C5 hybridoma line not only stain early somatic muscles such as the longitudinal fiber strands, but also show a strong signal in a posterior group of myogenic cells associated with the hindgut in the caudal papilla (the 016C6 clone used in all the myosin-HC staining experiments described above shows stronger affinity to longitudinal, cardial, and cephalic muscles than to gut muscle pioneers). At late stage 4 , these cells show significant myosin-HC 017C5 signal and form a layer surrounding the proctodaeum (Fig. 8d). Since these myogenic cells are not clearly separated, it is impossible to determine if they make up an early syncytium. We suggest, however, that they represent pioneers or precursors of visceral ring muscles that control the peristaltic movements of the intestine. The most posterior visible cells of this group are located ventrolaterally to the gut, but anteriorly to the MT1 cells and the first 2-3 mesoteloblast pairs (Fig. 8e, f). This suggests that gut muscles are generated in a non-teloblastic way. The signal is not seen more anteriorly in the gut muscle precursors which are, however, strongly stained by phalloidin. At stage 9, striation is seen in the circular gut muscles (Fig. 8g).

\section{Discussion}

By using the antibody clones myosin- $\mathrm{HC} 016 \mathrm{C} 6$ and $017 \mathrm{C} 5$ in combination with F-actin staining by phalloidin, we have shown that muscle cells with differing grades of differentiation can be distinguished in one and the same object. This greatly improves interpretation of the processes involved in forming the complex muscular system in analyses of series of developmental stages. Steffens et al. (1995) and Xie et al. (1994) have described a characteristic pattern of early muscle generation in the ventral thoracic embryonic segments of the grasshopper Schistocerca gregaria. These authors report single cell muscle pioneers that form cone-like processes towards the ectodermal insertion sites. One pair of transverse and one or two pairs of longitudinal muscle pioneers are seen per segment. These muscle pioneers serve as scaffold for the formation of multicellular muscle precursors by fusion of surrounding myoblast cells with the muscle pioneers. The transverse pioneers, for example, form the musculature of the ventral diaphragm by fusion with myoblasts. This pattern is also observed in crayfish in the segments of maxilla 1 and maxilla 2 during early stage 4 , where one pair of longitudinal and one pair of transverse muscle pioneers can be found. Transverse muscle pioneers are also found in the antennal segments.

Our data therefore indicates that a conserved pattern of early muscle founders is at least partly shared between insects and crustaceans. The development of a muscle precursor in the early longitudinal muscle strands of the crayfish thorax begins with the elongate mononucleate pioneer cell. This cell shows the specific myosin-HC signal likely caused by an increase in monomeric myosin in the cytoplasm. Next, F-actin fibers become visible. At the same time, further myosin-HC positive cells from the surrounding mesoderm become attached to the pioneer. In this way, 
a multicellular muscle precursor is formed in which the grade of differentiation of the individual cells can be seen from the relationship between $\mathrm{F}$-actin and myosin-HC reactivity. Unfortunately, we cannot determine the point at which cells fuse to form syncytial myotubes. The emergence of the striated sarcomere pattern of F-actin and myosin-HC positive fibers, which is typical of adult somatic musculature in most animals, is the next step observed in muscle precursor differentiation in crayfish. These findings show that the founder cell model for muscle patterning described in Drosophila (Baylies et al. 1998; Paululat et al. 1999; Campos-Ortega and Hartenstein 1997) may also apply to crayfish. However, we cannot draw conclusions about the mechanisms specifying muscle pioneers and fusion-competent myoblasts in this animal.

Unlike in dendrobranchiate crustaceans, the primordia of all the major adult muscle groups are laid down during embryogenesis in the crayfish. However, the temporal gap between the development of cephalic and postnaupliar intrinsic appendage muscles may well represent a relic of developmental features involved in locomotion of nauplius larvae. This staggering of cephalic muscle development compared to the remaining trunk, however, seems to be absent in direct developing embryos of the amphipods $P$. hawaiensis (Price and Patel 2008) and O. cavimana (Hunnekuhl and Wolff in preparation). We suggest that these characteristics were lost in the evolutionary lineage leading to the Peracarida.

We still do not have a clear picture of intrinsic appendage development in the marbled crayfish. It has been shown for isopod muscles (Kreissl et al. 2008) that intrinsic muscle precursors of the appendages are formed by single muscle founder cells in the appendages that can be detected by staining with the myosin-HC antibody 016C6. Our data confirm that this is the case for the development of longitudinal musculature of the trunk and in cardiac development. In the lobster Homarus ameri canus, intrinsic appendage muscles are laid down as syncytial precursors that stretch into the end of a multiarticulated appendage anlage to subdivide later into the individual muscles (Harzsch in press). In dendrobranchiate embryos, undivided muscle primordia reach from the trunk into the tip of the cephalic appendages and remain undivided in the free-living larva (Hertzler and Freas 2009). For the marbled crayfish, however, investigations concentrating on later stages are necessary.

The ventral longitudinal muscle strand of the marbled crayfish is laid down as segmentally repeated patches of muscle precursors from a row of longitudinal muscle pioneers that connect to each other via cellular extensions. The patches originate from single pioneer cells to which mesodermal cells are added as development proceeds. In
Fig. 6 Development of the pleon musculature: pleon anlagen of embryos stained with phalloidin Alexa 488 (green) and anti myosin $\mathrm{HC} \mathrm{Cy} 3$ (red). All images (only the left body half is shown) show the ventral view with the telson facing to the bottom of the page. Dotted lines indicate segmental furrows of the ectoderm. Muscle precursors of the dorsal strand (arrowheads) and the ventral strand (arrow) are shown. a Fibers of the dorsal and ventral longitudinal muscle strand are continuous. b The ventral strands show variations in fiber orientation. $\mathbf{c}$ In both the dorsal strand and an anterior portion of the ventral strand, single muscle units become distinguishable. d Single muscle units are visible throughout the pleon. e Further differentiation and increase in size is seen. $\mathbf{f} \mathbf{j}$ Virtual transverse sections through the pleon anlage. Yellow lines indicate the positions of the extended section planes shown in $\mathbf{k} \mathbf{t}$. $\mathbf{k}$ The cells of the early dorsal strand in pleomere 3 (Pl3) show only myosin signal. The dorsal myocyte patches are arranged metamerically along the AP axis. I Cells of the ventral strand in the same pleomere. F actin signal is seen in the lateralmost fibers, whereas medial cells are only positive for myosin. m Myoctes of the dorsal strand in pleomere 3 forming metameric fiber bundles with strong $\mathrm{F}$ actin signal (arrowheads). n F actin positive fibers of the ventral strand display the first lateral endings in the previously continuous strand (asterisks). o $\mathrm{F}$ actin fibers in the dorsal strand show striation. The signal intensifies at the ends of the muscle units (asterisks). p Dorsal section plane within the ventral strand. The central muscles (arrowheads) are distinguishable by their anterolateral endings (arrow) near the epidermal infold. q Section plane from the middle of the ventral strand. Posteriorly and ventromedially of the anterior central muscle endings shown in $\mathbf{p}$, the posterior end of this muscle is recognizable (arrow). Other fibers in the strand show striation but maintain their AP orientation at this stage (asterisk). $\mathbf{r}$ Ventral section through the ventral strand. The anterior oblique muscles can be seen. They originate at the epidermal infolds (asterisk) and protrude anteromedially to the middle of the next segment (stars). s The dorsal strand muscle units have broadened. t Ventral muscle strand at same stage. The central muscles (triangle) and transverse muscles (asterisk) are shown. In $\mathbf{u}$ and $\mathbf{v}$, the muscles of pleomere 3 have been three dimensionally reconstructed in IMARIS from the phalloidin signal and assigned different colors. The gut and right half of the pleon muscle complex are masked and hidden. Blue: dorsal pleon muscles $(\mathrm{dpm})$, turquoise: transverse muscles $(\mathrm{tm})$, light green: central muscles $(\mathrm{cm})$, orange: anterior oblique muscles with external arms (aom), pink: posterior loop of anterior oblique muscles (pla). Muscles of pleomere 2 and 4 are shown in dark green. Scale bars (a e) $100 \mu \mathrm{m}$, (f u) $20 \mu \mathrm{m}$

addition to the temporal continuum, a spatial gradient in differentiation can also be seen along the AP axis. This is most evident in stages 5 and 6 . However, clearly distinguishable muscle pioneers are not evident at these stages posterior to the last thoracic segments. In fact, these segments display strands of continuous F-actin fibers that reach into the caudal papilla. Nuclei are found in some cases within the strand, but their positions in relation to the segment borders, represented by ectodermal stripes of Engrailed, are variable. A group of muscle cells is found at the posteriormost end of the strand. The origin of this myogenic cell group in the caudal papilla appears to be independent of mesoteloblast activity, since it is located posteriorly of undivided mesoteloblast progeny. Evidence of posterior migration from anterior mesodermal regions was not found. We assume that the posterior longitudinal 


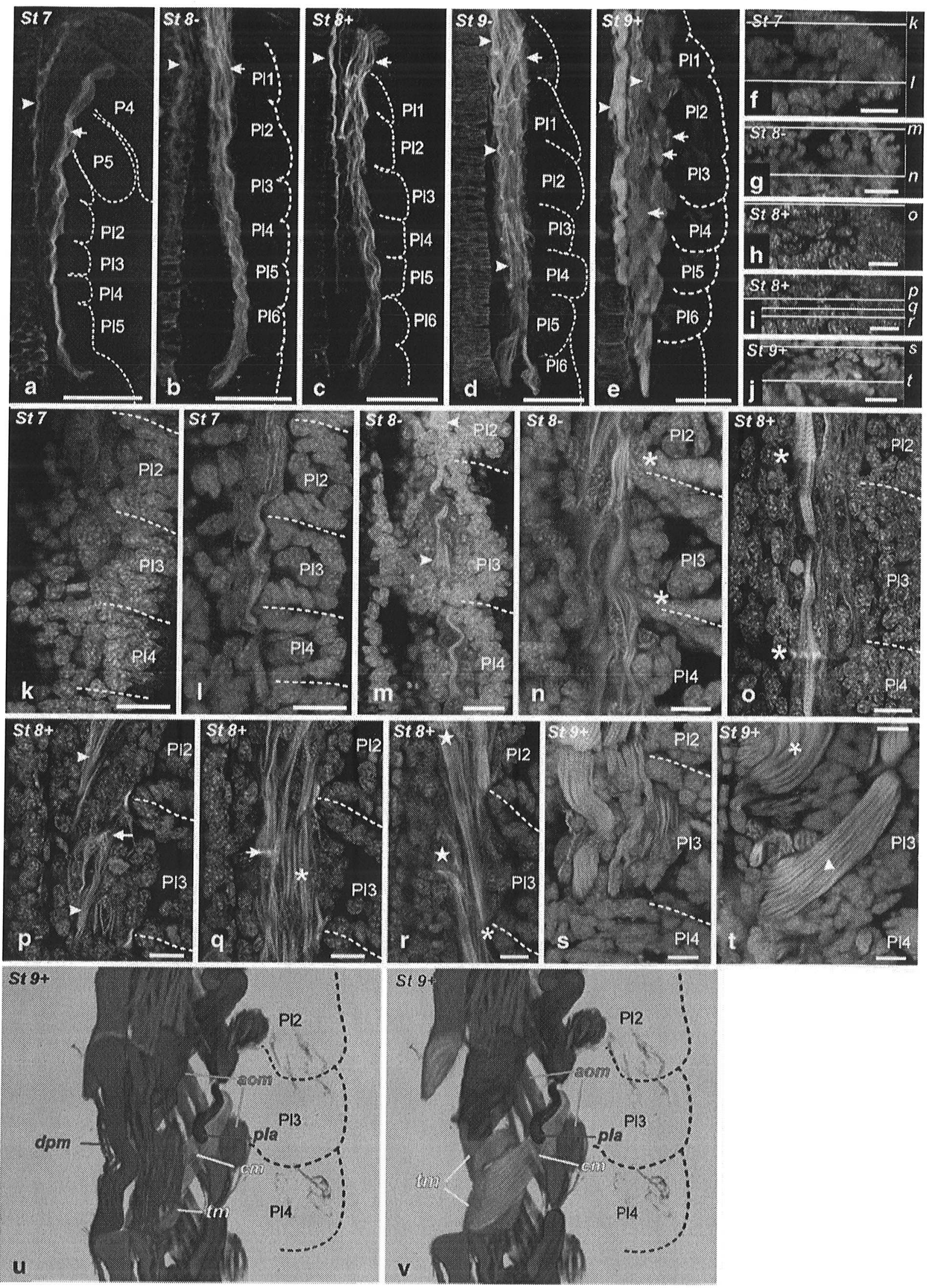



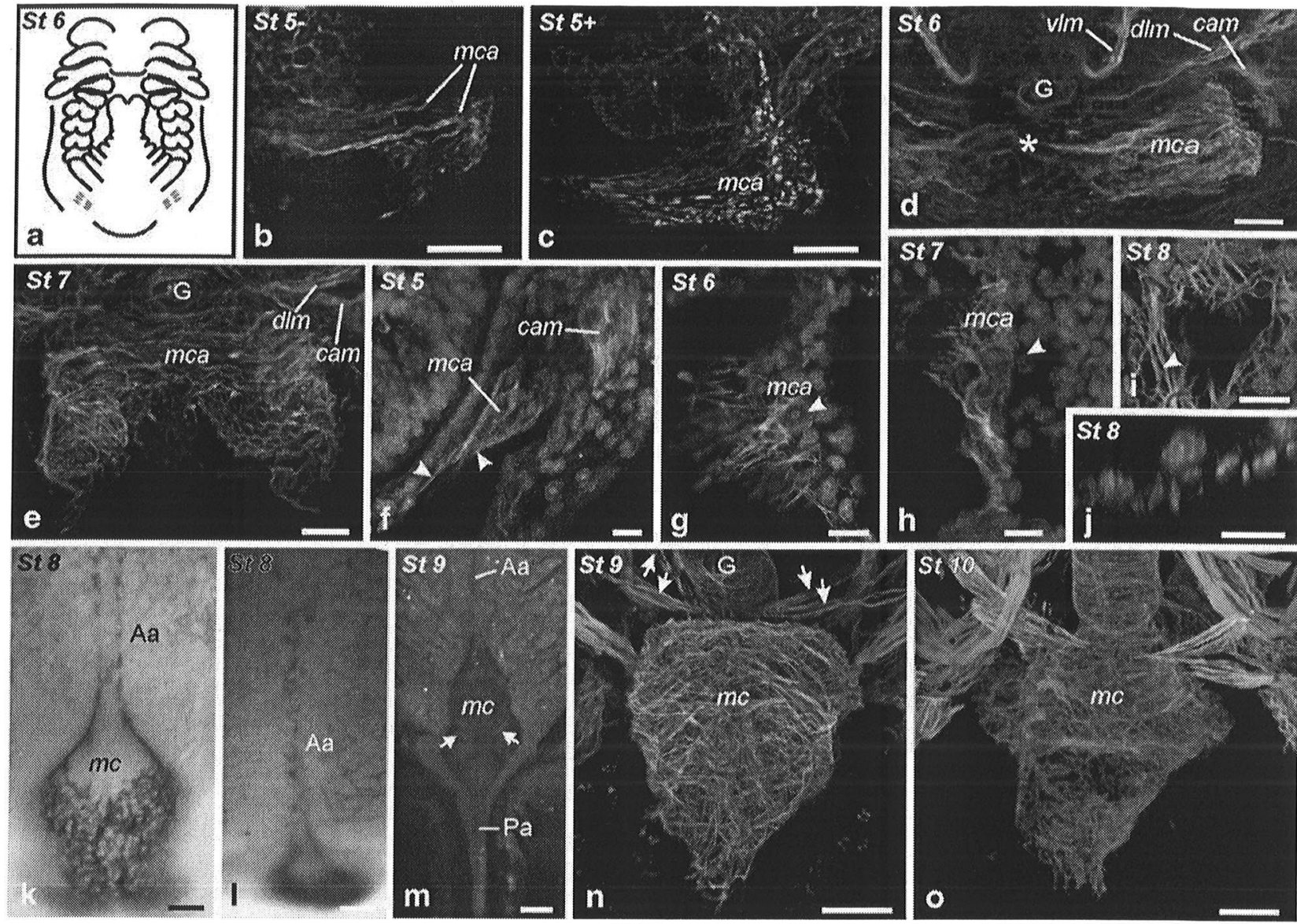

Fig. 7 Heart development: $\mathbf{a} \mathbf{j}$, $\mathbf{n}$ and o dissected embryos, $\mathbf{k} \mathbf{m}$ undissected eggs. a Schematic drawing of an embryo at stage 6 with the caudal papilla in its natural position. The heart precursors are indicated by red dotted lines. Orientation of the embryo is the same in all the images of this table. b e CLSM images of the embryonic heart precursors stained with phalloidin (green). b The first $\mathrm{F}$ actin fibers are visible at early stage 5 . c Increased number of fibers forming a broad band. d The fibers have formed a membrane that is closing medially (asterisk). The dorsal longitudinal muscle strand $(\mathrm{dlm})$ and the muscles of the carapace anlage (cam) are shown. e The membrane has broadened and formed dorsolateral extensions. f j Myocardial anlage ( $m c a$ ) stained for myosin $\mathrm{HC}$ and $\mathrm{F}$ actin, counterstained with Hoechst (light blue). f The early myocytes of the forming heart membrane are arranged in a lateral area of the caudal fold and extend dorsomedially with their fiber forming processes (arrowheads). $\mathrm{g}$, $\mathbf{h}$ The same group of cells increases and expands to the anterior and posterior. Additional cellular processes are seen protruding in different directions. These form the myocardial network. Myosin HC immuno reactivity is observed closer to the nucleus of the cardial myocytes (arrowhead) than the F actin signal. i Horizontal section of the dorsal myocardial layer. Striation (arrowhead) of the muscle fibers can be seen. $\mathbf{j}$ Saggital optical section shows the asymmetrical distribution of
F actin, which is stronger on the side of the network facing the cardial lumen. $\mathbf{k}$ m Stereo micrographs of embryos stained with myosin HC antibody and subsequently subjected to an alkaline phosphatase reaction. Dorsal views with anterior facing the top of the page. $\mathbf{k}$ Myocardium and posterior aorta $(\mathrm{Pa})$. The anterior aorta $(\mathrm{Aa})$ shows two parallel rows of cells displaying myosin $\mathrm{HC}$ signal. I More anterior view of same object. $\mathbf{m}$ Myocardium, anterior, and posterior aorta. A pair of ostia (arrows) can be seen. $\mathbf{n}$ Heart stained with anti myosin HC (red) and phalloidin (green), dorsal view. Embryo is oriented as in a. The myocardium is a three dimensional network of multiple muscle fibers. Anteriorly, four alary muscle primordia can be seen. $o$ The heart and the adjacent muscle groups of a stage 10 embryo have each been reconstructed and assigned different colors: red myocardium, yellow alary muscles, green circular gut musculature, blue carapace anlagen musculature, pink longitudinal muscle appara tus of the trunk). The myocardium at this stage forms a condensed network of fibers. Fibers also take up an extensive part of the heart lumen. Orientation as in a but in ventral view. Letters in the upper left corners identify the developmental stages. cam carapace anlagen muscles, $\mathrm{dlm}$ dorsal longitudinal muscles, $\mathrm{G}$ gut, $\mathrm{mc}$ myocardium, $\mathrm{Pa}$ posterior aorta, $v / m$ ventral longitudinal muscles. Scale bars (b e) $100 \mu \mathrm{m}$, (f j) $20 \mu \mathrm{m},(\mathbf{k}$ m) $100 \mu \mathrm{m}$, (n o) $200 \mu \mathrm{m}$ muscle origin is formed by cells of the telson mesoderm (Alwes and Scholtz 2006), which is laid down behind the teloblast cell rows during gastrulation (Weygoldt 1961) and later forms musculature in the telson. We propose that the muscle cells in question form cellular processes that comprise a considerable part of the longitudinal muscle strands in the posterior thoracic and the pleonal segments. These processes are then elongated as the muscle cells 

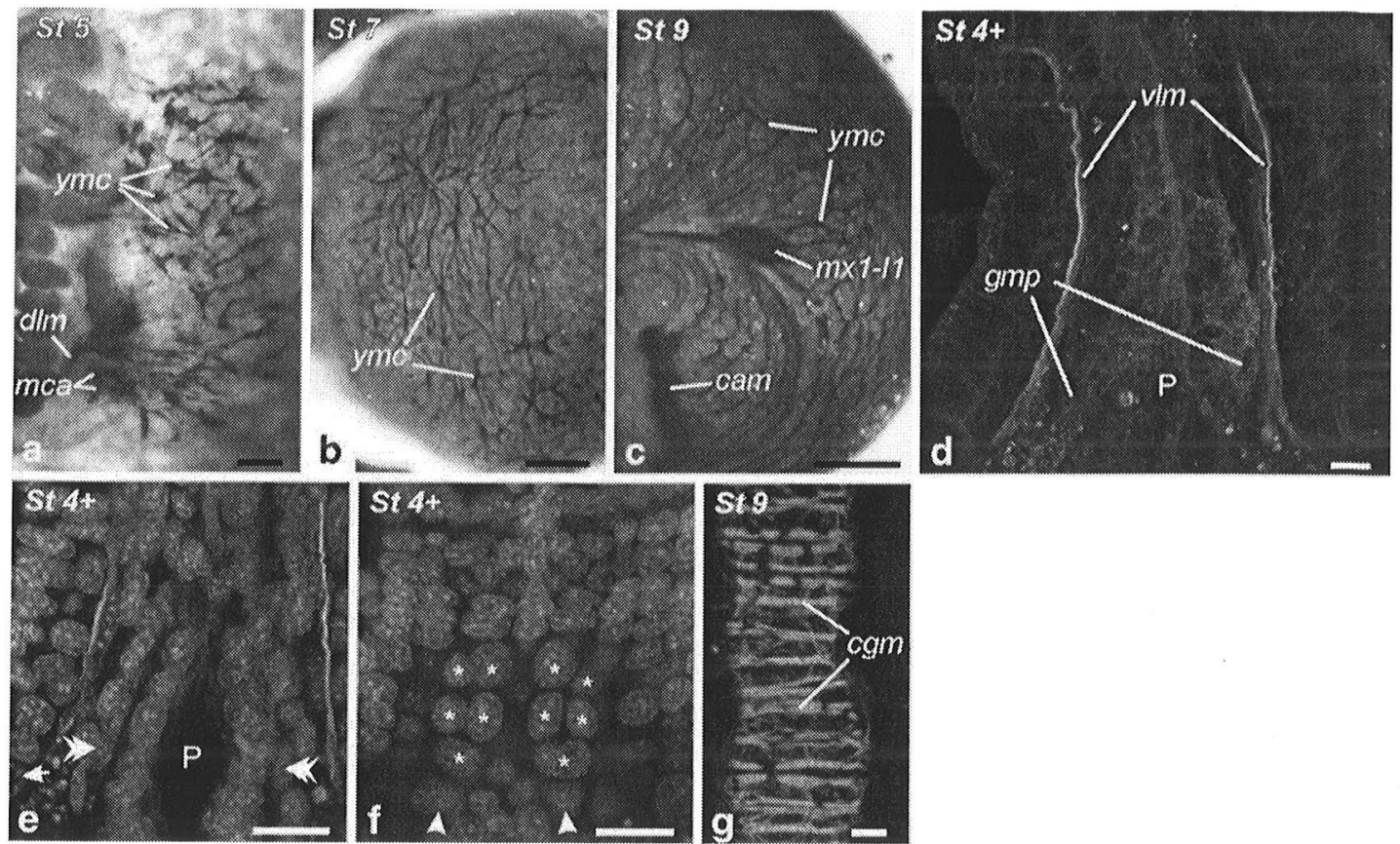

Fig. 8 Visceral muscle development: a c dechorionated eggs stained with anti Myosin $\mathrm{HC}$ 017C5 and subjected to secondary staining with the alkaline phosphatase system (dark blue). Embryos are shown in their natural position with the caudal papilla flexed anteriorly (Fig. 6a). a Star shaped cells showing strong myosin $\mathrm{HC}$ signal are visible on the yolk surface on both sides of the carapace anlage. The cells carry filamentous projections which extend distally from the nucleus. b Fine myocyte projections form a network that covers the yolk. $\mathbf{c}$ The fiber network diversifies and forms an area of converging fibers near the lateral cephalic muscle of the second maxilla ( $m \times l l i)$, which extends dorsally. d g Dissected embryos stained with anti myosin HC 017C5 (red), phalloidin (green), and Hoechst (light blue, in e and $\mathbf{f}$ ). The posterior end of the caudal papilla faces the bottom of the page in these

images. d The anti myosin HC signal identifies a group of cells surrounding the posterior part of the gut in the caudal papilla. $\mathrm{F}$ actin is mainly seen in the ventral longitudinal muscle fibers left and right. $\mathbf{e}$ A horizontal section showing the posteriormost cells of the forming gut muscles (double arrows) and partly the left mesoteloblast cell 1MT2. f More ventral section of the same object. The ventral mesoteloblast pair 1MT1 and rMT1 (arrowheads) and their progeny (asterisks) are shown. $\mathrm{g}$ Forming circular myocytes of the gut. Letters in the upper left corners identify the developmental stages. cam carapace anlagen muscles, cgm circular gut muscles, $\mathrm{dlm}$ dorsal longitudinal muscle, gmp gut muscle precursors, $m c a$ myocardial anlage, $P$ proctodaeum, $v l m$ ventral longitudinal muscles, ymc yolk muscle cells. Scale bars (a) $100 \mu \mathrm{m}$, (b c) $200 \mu \mathrm{m},(\mathbf{d}$ g) $20 \mu \mathrm{m}$

themselves move posteriorly as a result of the addition of mesodermal segment primordia from the mesoteloblasts.

No data are yet available on early longitudinal muscle formation in the postnaupliar region of dendrobranchiates (Hertzler, personal communication). Kiernan and Hertzler (2006) describe a pair of phalloidin-positive strands that extend anteriorly from the telson anlage which they interpret as possible nerves of the furcal spines. In both branchiopods (Blanchard 1986) and malacostracans (stomatopods: Fischer and Scholtz 2010; decapods: Biffis, personal communication), posterior pioneer neurons have been described as part of the developing central nervous system, neural cells which lie at the posterior end of the caudal papilla in a pair-wise arrangement. These pioneer neurons form the posterior connectives of the ventral nerve cord by sending axons anteriorly, while the anterior connectives are formed by anterior-posterior progression from the developing ganglia. This mechanism was most likely present in the last common ancestor of malacostracans but has not been found in amphipods or isopods so far (Wolff, unpublished data).

We suggest that the mechanism responsible for the formation of early longitudinal fibers from posterior myocytes is similar to the mode of posterior connective development. The simultaneous formation of nervous or muscular tissue from the anterior and posterior makes sense when we consider the necessity of posterior sensory input in a free-swimming nauplius or a muscularized trunk for the tail-flip reflex of a dendrobranchiate protozoea. These features may well also be relics inherited from ancestors with free-swimming larvae and lost within malacostracans in the lineage leading to Amphipoda and Mancoida. The development of the dorsal longitudinal muscle strand is entirely gradual. Segmentally repeated cell clusters are seen at dorsal positions within the mesoteloblast progeny. Muscle pioneers then become visible within these clusters and the surrounding cells are recruited to the precursor. 
Crayfish pleon muscles at stage 9 reflect the general pattern first described for larval stages of caridean shrimp and crabs (Daniel 1930a-c; Young 1959) which also applies to the adult pleon musculature of the dendrobranchiate Penaeus setiferus as well as to dendrobranchiate larvae (Hertzler and Freas 2009). This pattern may well be important for the flipping movement of the pleon, which is typical for many adult decapods or larvae. In this case, it might have been established in the lineage leading to decapods. However, we have no knowledge of muscle patterning in other malacostracans

Cardiac development in crayfish strongly resembles cardiogenesis in P. varians (Weygoldt 1961). The cells of dorsal mesodermal regions move dorsally with muscular processes and form a membrane below the dorsal epidermis which subsequently closes to form a contractile, myocardial sack. The exact spatial relationship between the myocardial pioneer cells and the thoracic somites is difficult to discern because they are passively shifted to the posterior as the number of trunk segments anterior to the caudal fold increases. The heart-forming cells are positioned laterally away from the thoracic mesodermal somites when first detectable by antibody and phalloidin staining. It is reasonable, however, to assume that these cells represent mesoteloblast derivatives, though this could not be shown in this study. In all arthropods studied so far, the heart tissue is formed from a dorsal subset of the mesoderm (Hartenstein and Mandal 2006, Janssen and Damen 2008). In vivo-labeling experiments on mesodermal cells of the amphipod $O$. cavimana provide clues that the dorsal mesoteloblast pair MT4 gives rise to the heart (Hunnekuhl and Wolff, in preparation). The early development of the heart is still of particular interest and deserves to be dealt with in further investigations. Crayfish and other malacostracans including all the remaining decapods and euphausiaceans share the feature of a bulbous heart in the adult, in contrast to the tubular heart of stomatopods, leptostracans, or peracarids (Wirkner and Richter 2009a, b). The mechanisms involved in the formation of the myocardium in these groups remain to be investigated. Interestingly, prospective cells of the anterior aorta of the crayfish heart show a myosin-HC signal at stage 8 that is lost as development proceeds. Similar findings have been reported for lobster arteries (Wilkens et al. 1997; Wilkens 1999). These cells may be part of a general mechanism of cell recruitment for the formation of a tubular heart but may later be lost when pumping is taken over by the bulbous myocardium. In other regions of the crayfish dorsal vessel, such as the posterior aorta, a temporary increase in myosin-HC protein as seen here was not observed.
Our survey also produced data on visceral musculature Muscle development in higher metazoans is characterized by a split into somatic and visceral myogenic cell populations (see for example Bodmer 1993). Visceral muscles serve as contractile components for the functioning of inner organs in many animals. They are responsible, for example, for the peristaltic movement of the intestinal tract. The formation of a fibrillar network covering the yolk was an unexpected finding at this stage. However, it explains the contractile activity of the yolk surface observed in living eggs. These contractile cells may well lead to the myoepithelial layer of the adult midgut gland and, at this time in development, facilitate the transport of nutrients from the yolk to the developing tissues. Mesodermal cells that become associated with the yolk during the development of $P$. varians have been reported by Weygoldt (1961).

The specificity of the $017 \mathrm{C} 5$ antibody to early gut muscleforming cells may be explained by its relatively strong affinity to characteristic isoforms of the myosin-HC protein that is expressed in the gut muscle pioneers and precursors at a certain time in development. As in the case of longitudinal muscle pioneers, the posteriormost detectable gut muscle founders are located posteriorly of the stereotypically arranged descendants of the ventralmost mesoteloblast MT1. It therefore seems unlikely that early visceral myocytes of the gut are formed by this cell. Possibly, gut muscle precursors are derived from median cells of the telson mesoderm.

The development of muscular tissue in non-model arthropods is a very young field of study. Modern approaches to developmental processes in new organism systems normally rely on the analysis and comparison of gene expression. However, morphological resolution is an important prerequisite for the interpretation of these data. We believe that our investigations provide an informative picture of myogenesis in the crayfish which will form a useful basis for molecular developmental studies.

Acknowledgements The 4D9 anti EN/INVECTED monoclonal an tibody developed by Corey Goodman (University of California, Berkeley) was obtained from the Developmental Studies Hybridoma Bank, which was developed under the auspices of the NICHD and is maintained by The University of Iowa, Iowa City, IA 52242. We also express our gratitude to Frederike Alwes for instructions on crayfish care, egg handling, dissection, and staining. Thanks also to Lucy Cathrow for improving the English of the manuscript. This study was supported by the DFG grant Ri837/8 1 to SR, Wo1461/1 1 to CW.

\section{References}

Abzhanov A, Kaufman TC (2000) Evolution of distinct expression patterns for engrailed paralogues in higher crustaceans (Mala costraca). Dev Genes Evol 210:493 506 
Alwes F, Scholtz G (2006) Stages and other aspects of the embryology of the parthenogenetic marmorkrebs (Decapoda, Reptantia, Astacida). Dev Genes Evol 216:169 184

Baylies MK, Bate M, Gomez MR (1998) Myogenesis: a view from Drosophila. Cell 93:921 927

Bodmer R (1993) The gene tinman is required for specification of the heart and visceral muscles in Drosophila. Development 118:719 729

Blanchard CE (1986) Early development of the thorax and nervous system of the brine shrimp Artemia. Dissertation, University of Leicester, p 68

Campos Ortega JA, Hartenstein V (1997) The embryonic develop ment of Drosophila melanogaster. Springer, Berlin, p 405

Dalbis A, Pantaloni C, Bechet JJ (1979) Electrophoretic study of native myosin isozymes and of their subunit content. Eur J Biochem 99:261 265

Daniel RJ (1930a) The abdominal muscles of the shore crab (Carcinus maenas Fabr.) and the zoea and megalopa stages. Proc Trans Liverpool Biol Soc 45:50 56

Daniel RJ (1930b) Comparative study of the abdominal muscles in Malacostraca. Part 1. The main ventral muscles of the typical abdominal segments. Proc Trans Liverp Biol Soc 45:57 71

Daniel RJ (1930c) The abdominal muscular systems of the zoea and mysis stages of the shrimp (Crangon vulgaris Fabr.) and their bearing on phylogeny. Proc Trans Liverpool Biol Soc 44:95 109

Dohle W (1970) Die Bildung und Differenzierung des postnauplialen Keimstreifs von Diastylis rathkei (Crustacea): I Die Bildung der Teloblasten und ihrer Derivate. Z Morphol Tiere 67:307 392

Dohle W (1972) Über die Bildung und Differenzierung des post nauplialen Keimstreifs von Leptochelia spec. (Crustacea, Tanai dacea). Zool Jb Anat 89:503 566

Fischer A, Scholtz G (2010) Axogenesis in the stomatopod crustacean Gonodactylaceus falcatus (Malacostraca). Invertebr Bio 129:59 76

Gerberding M, Browne WE, Patel NH (2002) Cell lineage analysis of the amphipod crustacean Parhyale hawaiensis reveals an early restriction of cell fates. Development 129:5789 5801

Hartenstein V, Mandal L (2006) The blood/vascular system in a phylogenetic perspective. BioEssays 28:1203 1210

Harzsch S, Kreissl S (in press) Myogenesis in the thoracic limbs of the American lobster. Arthr Struct Dev, doi:10.1016/j.asd.2010.06.001

Hertzler PL, Freas WR (2009) Pleonal muscle development in the shrimp Penaeus (Litopenaeus) vannamei (Crustacea: Malacostraca: Decapoda: Dendrobranchiata). Arthr Struct Dev 38:235 246

Janssen R, Damen WGM (2008) Diverged and conserved aspects of heart formation in a spider. Evol Dev 10:155 165

Kiernan DA, Hertzler PL (2006) Muscle development in dendrobranchiate shrimp, with comparison with Artemia. Evol Dev 8:537 549

Kreissl S, Uber A, Harzsch S (2008) Muscle precursor cells in the developing limbs of two isopods (Crustacea, Peracarida): an immunohistochemical study using a novel monoclonal antibody against myosin heavy chain. Dev Genes Evol 218:253 265

Oishi S (1959) Studies on the teloblasts in the decapod embryo. 1. Origin of teloblasts in Heptacarpus rectirostris (Stimpson). Embryologica 4:283 309

Oishi S (1960) Studies on the teloblasts in the decapod embryo. 2. Origin of teloblasts in Pagurus samuelis (Stimpson) and Hemi grapsus sanguineus (de Haan). Embryologica 5:270 282
Paululat A, Holz A, Renkawitz Pohl R (1999) Essential genes for myoblast fusion in Drosophila embryogenesis. Mech Dev 83:17 26

Price AL, Patel NH (2008) Investigating divergent mechanisms of mesoderm development in arthropods: the expression of $P h$ twist and Ph mef2 in Parhyale hawaiensis. J Exp Zool B Mol Dev Evol 310:24 40

Richter S, Scholtz G (2001) Phylogenetic analysis of the Malacostraca (Crustacea). J Zool Syst Evol Res 39:113 136

Scholtz G (1990) The formation, differentiation and segmentation of the post naupliar germ band of the amphipod Gammarus pulex $\mathrm{L}$. (Crustacea, Malacostraca, Peracarida). Proc R Soc Lond 239:163 211

Scholtz G (1992) Cell lineage studies in the crayfish Cherax destructor (Crustacea, Decapoda): germ band formation, segmentation, and early neurogenesis. Roux's Arch Dev Biol 202:36 48

Scholtz G (2002) The Articulata hypothesis or what is a segment? Org Divers Evol 2:197 215

Scholtz G, Braband A, Tolley L, Reimann A, Mittmann B, Lukhaup C, Steuerwald F, Voigt G (2003) Parthenogenesis in an outsider crayfish. Nature 421:1431 1434

Seitz R, Vilpoux K, Hopp U, Harzsch S, Maier G (2005) Ontogeny of the Marmorkrebs (marbled crayfish): a parthenogenetic crayfish with unknown origin and phylogenetic position. J Exp Zool 303A:393 405

Steffens G, Xie F, Kutsch W, Reichert H (1995) Segmental differentiation processes in embryonic muscle development of the grasshopper. Roux's Arch Dev Biol 204:453 464

Vilpoux K, Sandeman R, Harzsch S (2006) Early embryonic development of the central nervous system in the Australian crayfish and the Marbled crayfish (Marmorkrebs). Dev Genes Evol 216:209 223

Vogt G, Tolley L, Scholtz G (2004) Life stages and reproductive components of the Marmorkrebs (marbled crayfish), the first parthenogenetic decapod crustacean. J Morph 261:286 311

Weygoldt P (1958) Die Embryonalentwicklung des Amphipoden Gammarus pulex pulex (L.). Zool Jb Anat 77:51 110

Weygoldt P (1961) Beitrag zur Kenntnis der Ontogenie der Dekapoden: Embryologische Untersuchungen. Zool Jb Anat 79:223 270

Wilkens JL, Yazawa T, Cavey MJ (1997) Evolutionary derivation of the American lobster cardiovascular system: an hypothesis based on morphological and physiological evidence. Invertebr Biol 116:30 38

Wilkens JL (1999) Evolution of the cardiovascular system in Crustacea. Am Zool 39:119 214

Wirkner CS, Richter S (2009a) Evolutionary morphology of the circulatory system in Peracarida (Malacostraca; Crustacea). Cladistics 25:1 25

Wirkner CS, Richter S (2009b) The circulatory system in malacos traca: evaluating character evolution on the basis of differing phylogenetic hypotheses. Arthr Syst Phyl 67:57 70

Wolff C, Scholtz G (2002) Cell lineage, axis formation and the origin of germ layers in the amphipod crustacean Orchestia cavimana. Dev Biol 250:44 58

Xie F, Garzino V, Herianos S, Meier T, Reichert H (1994) Embryonic expression of muscle specific antigens in the grasshopper Schistocerca gregaria. Roux's Arch Dev Biol 204:141 145

Young JH (1959) Morphology of the white shrimp Penaeus setiferus (Linnaeus, 1758). Fishery Bulletin US 59:1 168 